\title{
LA LITERATURA APÓCRIFA JUDÍA EN EL NUEVO TESTAMENTO \\ LA CARTA DE JUDAS
}

\begin{tabular}{c}
\hline Pedro P. Soto Canales* \\
Universidad Católica Sedes Sapientiae \\
\hline
\end{tabular}

Fecha de recepción: septiembre de 2012 Fecha de aceptación: octubre de 2012

Resumen: El presente trabajo tiene como finalidad demostrar cómo la literatura apócrifa judía fue utilizada inicialmente como un medio por el cual los primeros cristianos —especialmente de origen judío- hicieron llegar sus preocupaciones, orientaciones y enseñanzas doctrinales a las primeras comunidades que iban desarrollándose dentro y fuera de la Palestina de los primeros siglos. Especialmente, el estudio se centra en la carta de Judas, en donde podemos apreciar referencias a escritos apócrifos judíos como el libro de Henoc y la Ascensión de Moisés. Finalmente, se busca demostrar cómo la referencia a ciertos escritos no canónicos no es un impedimento o peligro doctrinal, pues deben ser considerados como una fuente para conocer el ambiente sociocultural y religioso en donde comenzó a desarrollarse paralelamente, tanto el judaísmo como el cristianismo.

* Pedro Soto Canales es coordinador del Área de Historia del pregrado de la Universidad Católica Sedes Sapientiae. Es licenciado en Educación, en las especialidades de Ciencias Históricos Sociales y Ciencias Religiosas por la Universidad Marcelino Champagnat y con Maestría en Historia Económica por la UNMSM. Ha publicado en esta revista "La enseñanza rabínica en la Palestina de los primeros siglos de la era cristiana» (Studium Veritatis, ańo 7, N. os $12-13,2009$, pp. 89-112). 
Palabras Clave: apócrifo, Hisonim, Canon, apocalíptico, Tanaka, Torà, Nebiìm, Ketubiìm, Henoc, Ascensión de Moisés, Judas.

ABSTRACT: The purpose of this work is to demonstrate how the Jewish apocryphal literature, was used initially by the first Christians —especially of Jewish origin - to account for their concerns, orientations and doctrinal teachings to the first communities that developed inside and outside Palestine in the first centuries. In particular, the study focuses on the letter of Jude in which we can see references to Jewish apocryphal writings such as the Book of Enoch and the Assumption of Moses. And finally, it we seek to demonstrate how the reference to certain non-canonical writings is neither an impediment nor a doctrinal danger, but a source to learn about the sociocultural and religious environment where, both Judaism and Christianity began to develop in parallel.

KeYwords: apocryphal, Hisonim, apocalyptic Canon, Tanaka, Torà, Nebiìm, Ketubiìm, Henoc, Assumption of Moses, Judas.

\section{INTRODUCCIÓN}

7 presente trabajo tiene como finalidad demostrar cómo la literatura apócrifa judía fue en ciertas ocasiones utilizada por los primeros cristianos -especialmente de origen judío- como medio comparativo y/o alegórico para transmitir preocupaciones, orientaciones y enseñanzas doctrinales a las primeras comunidades que iban desarrollándose dentro y fuera de la Palestina de los primeros siglos. Especialmente el estudio se centra en la carta de Judas, en donde se puede apreciar referencias a libros apócrifos judíos como el libro de Henoc y la Ascensión de Moisés. 
La estructura de la investigación consta de cinco partes. En la primera, se desarrolla, de manera breve, la concepción y uso que se daba a la palabra «apócrifo» en el mundo grecolatino, y posteriormente, en el mundo cristiano y judío antiguo. En la segunda, se describe el contexto situacional en que surge la literatura apócrifa judía. En un tercer momento, se ubican los principales momentos de la historia de Israel, en donde se registra el reconocimiento de los libros inspirados, con miras a la formación del canon judío. En la cuarta parte, se identificará, en la carta de Judas, las referencias a libros apócrifos judíos utilizados por el autor y las razones de su uso. Finalmente, en la quinta, se demostrará que la referencia a ciertos escritos fuera del canon no es un impedimento o peligro doctrinal, ya que es posible considerarlos como fuente para conocer el ambiente sociocultural y religioso en donde comenzó a desarrollarse paralelamente tanto el judaísmo rabínico como el cristianismo.

\section{EL MUNDO «APÓCRIFO» JUDÍO}

\section{I. El TÉRMINO APÓCRIFO}

De origen griego, la palabra apócrifo $(\alpha \pi \mathrm{o} \chi \rho \uparrow \phi о \sigma)$ pasó posteriormente al latín como apocryphus. En ambos idiomas tiene los mismos significados: 'fabuloso', 'supuesto', 'fingido', 'oculto'. En el mundo grecolatino se usaba para identificar a ciertos $\operatorname{libros}^{1}$ que no eran de uso popular, pues se consideraba que habían «sido escondidos por tratarse de revelaciones secretas» (Arens 1990:124). En otras palabras: «Servía en la antigüedad para designar los libros que se destinaban exclusivamente al uso privado de

1 El término original sería rollo, omitido por motivo de comprensión. 
los adeptos a una secta o iniciados en algún misterio. Tales eran entre los romanos los libros Sibilinos y el Ius Pontificum. Después esta palabra vino a significar libro de origen dudoso, cuya autenticidad se impugnaba» (Santos 1999: 1).

Desde sus inicios, el cristianismo antiguo adoptó el término del mundo en el que empezaba a desenvolverse. La finalidad fue hacer referencia a aquellos libros que iban apareciendo en las comunidades cristianas, los cuales eran de dudosa procedencia y/o formaban parte del patrimonio literario de algún grupo que se encontraba separado o cuestionado por la Iglesia oficial. Posteriormente, la Iglesia reconoció también como apócrifos a los que provenían del mundo judío y no formaban parte de la $T a N a K,{ }^{2}$ o Biblia hebrea. ${ }^{3}$

Pero, ¿cuál era el riesgo o peligro que enfrentaba la Iglesia — y también el judaísmo del momento- frente a la circulación de dicha literatura? Al respecto el P. Eduardo Arens considera que:

Se presentaban como Escritura inspirada por Dios, pero que en definitiva no fueron reconocidos como tales [...] muchos se presentan como obras de algún personaje importante [bíblico que] pretenden justificar una visión teológica diferente de la tradicional y oficial, es decir se propone expresar la identidad de un grupo [...] algunos son productos de la ficción piadosa, otros lo son de una determinada corriente teológica. (1990: 124-125)

2 Acróstico compuesto con las primeras letras correspondientes a los tres bloques de libros que comprenden la Biblia hebrea: Torá (Pentateuco), Nebiím (Profetas) y Ketubiim (Escritos o rollos).

3 Tampoco formarían parte del Antiguo Testamento en la Biblia católica. 
A diferencia del cristianismo, la reacción del judaísmo de finales del siglo I d. C. fue más rápida con respecto a estos libros que circulaban en su ambiente religioso-cultural. Aunque más adelante será tratado detalladamente, el judaísmo posterior a la destrucción del Templo (70 d. C.), denominó con la palabra hebrea sefarim hisonim a «los que están fuera» de la aceptación canónica. Además, la prohibición de la lectura de los libros hisonim -especialmente de manera pública - fue decisivo para no ser reconocidos dentro de la literatura oficial. Inclusive, nadie podía estudiarlos, pues se condenaba a la «exclusión del mundo futuro» (Diez 1984:97) como lo enseñaba el rabino Aqiba (50-135 d. C.).

En conclusión, tanto el cristianismo antiguo como el judaísmo rabínico, que comenzaban a desarrollarse en el primer siglo de la era cristiana, tuvieron que identificar, frente a una vasta literatura que iba apareciendo dentro de la Iglesia (asamblea) y la Qahal (comunidad) cuáles eran de inspiración divina y cuáles no los eran. A estos últimos — según sea el caso- se les llamó apócrifos e hisonim.

\subsection{LA LITERATURA APÓCRIFA JUDÍA}

Se entiende por literatura apócrifa ${ }^{4}$ judía al conjunto de libros de origen judío o judeocristiano que aparecieron en un determinado momento de la historia del pueblo hebreo. Estos volúmenes se presentaron como inspirados y adjudicando la autoría a un personaje bíblico del Antiguo Testamento.

Aunque llegaron a ser más de un centenar de libros, solamente han quedado fragmentos de copias hechas a partir de los originales y menciones anónimas de los mismos. Los libros con estas características circularon especialmente en el mundo cristiano.

4 Omitiré la palabra hisonim por apócrifo. 
Cronológicamente, la literatura apócrifa judía floreció entre el siglo II a. C. hasta el siglo II d. C. Esto significa en momentos en que Israel era ocupada y administrada por los griegos (época helenista) y los romanos (época imperial). Muchas de estas obras nacen «del roce entre la cultura griega extendida por Alejandro Magno en el siglo II a.C. y los ecos de las culturas orientales tanto babilónicas, persas como egipcias» (Chico 2006:91).

A partir del contexto situacional anteriormente descrito, se puede comprender que, unido a la riqueza plural teológica que contenían estos libros, iba la invitación a un compromiso político y social por parte del judío piadoso. Así también lo consideraba el orientalista y hebraísta español David Gonzalo Maeso cuando argumentaba que una de las finalidades de los apócrifos judíos era el de «mover a la observancia de las patrias leyes y levantar el espíritu decaído de sus correligionarios, mediante el anuncio del próximo cumplimiento de los vaticinios proféticos y la inminencia del reino mesiánico» (1959:42).

Para ello se hizo uso de los diversos géneros literarios, de manera especial el apocalíptico, ${ }^{5}$ que estaba «muy extendido en el judaísmo y atraía a muchos individuos de diversas sectas» (Diez 1984:97). La popularidad de este género literario descansaba en el propósito de «infundir esperanza en una situación desesperante, dar ánimo cuando parecía mejor renunciar, afirmar la fe en momentos en que hay dudas sobre la justicia divina» (Arens

5 Consiste sustancialmente en la presentación de una doctrina por medio de una revelación. Un personaje celestial se aparece y en una visión o sueño da a conocer al vidente una serie de verdades [...] Este género se presta a presentar de forma viva un mensaje y, especialmente, a autorizarlo, al ofrecerlo como proveniente directamente del mundo de Dios. [...] Es un recurso que periódicamente aparece en la historia, incluso en nuestros días, para ofrecer seguridad, especialmente en épocas de crisis (Rodríguez 2002:155). 
1990: 77$){ }^{6}$

Los contenidos escatológicos ${ }^{7}$ eran los más resaltantes en el género apocalíptico judío durante la época helenista-romana. Así tenemos la historia como escenario triunfal de la acción de Dios, en donde Israel es su instrumento de manifestación; la preparación en este mundo de pruebas, para alcanzar el mundo de Dios; la contraposición del bien y el mal en el actuar humano; aceptar la voluntad divina en la vida cotidiana y, la aparición de un Mesías, un descendiente del rey David.

Por otro lado, en la actualidad muchos especialistas han clasificado los libros apócrifos judíos en tres categorías: didácticos, históricos y apocalípticos. Sin embargo, la clasificación puede ser diversa si se tiene en cuenta otros criterios aparte de los géneros literarios.

Alejandro Diez Macho (1984) considera hasta tres formas de clasificar los libros apócrifos judíos. Estos son género literario (narrativos, testamentos, apocalípticos, salmos y oraciones), círculo religioso de origen (fariseos, comunidades de Qumrán, etc.) y lugar de procedencia (Palestina o la diáspora). Es importante anotar que esta última clasificación no solamente abarca la tierra de Israel, sino cualquier parte del mundo antiguo en donde existiera una comunidad judía (por ejemplo, tenemos Egipto, Siria, etc.).

$6 \quad$ El mismo autor cita los libros de Daniel (A. T.) y el Apocalipsis (N. T.), como ejemplos de literatura apocalíptica canónica, y que surgen en tiempos de crisis y persecución. Así, Daniel es escrito en tiempos de Antíoco IV (167-164 a. C.) y el Apocalipsis de Juan, en tiempos de Domiciano (90 d. C.).

7 Es la ciencia del más allá (skatos, lo último, en griego; logos, tratado). Como ciencia teológica o parte de la teología cristiana, se dedica a explorar, interpretar y exponer los misterios que se refiere a los últimos tiempos o a las últimas realidades de los hombres (Chico 2006:466). 
Más actual, Antonio Rodríguez Carmona (2002) les da varias calificaciones. Los llama escritos en hebreo, relecturas actualizadas de la Biblia, adaptaciones de obras paganas, tipo oracional, provenientes de la diáspora, círculos religiosos, anti-helenistas, pensamiento judío, etc.

\subsection{El libro de Henoc y la Ascensión de Moisés}

Entre los principales libros apócrifos judíos - apocalípticos- que se difundieron durante los siglos II a.C. y II d.C. existen dos que tuvieron mucha influencia tanto en el ambiente judío como en el cristiano. El primero es el de Henoc y el segundo, la Ascensión de Moisés. A continuación se explicarán sus particularidades.

Existieron tres libros de «Henoc» diferentes por el idioma en que se han transmitido. Estos son el Henoc etiópico (el más antiguo), el Henoc eslavo y el Henoc hebreo. De ellos, el que analizaremos en el presente trabajo es el primero.

Como ya se hizo referencia, los libros llevaban el nombre de algún personaje principal dentro de las tradiciones judías. ${ }^{8}$ En este caso, la pregunta que se evidencia es conocer quién es Henoc. La historia de este personaje se encuentra en el capítulo cinco del libro del Génesis, en el que se indica como el séptimo en la lista de los descendientes de Adán.

El Henoc etiópico fue redactado por judíos palestinos entre el siglo II a. C. Según la mayoría de los estudiosos, el Henoc etiópico fue el más interesante y conocido, ya que contenía el cuerpo doctrinal y religioso del judaísmo en los tiempos de crisis social y política. Consta de 105 capítulos, divididos en seis sesiones o partes, las mismas que no llevan una uniformidad en el contenido:

8 De la misma manera será entre los libros apócrifos cristianos. 

a. Sobre los ángeles (1-36)
b. Sobre las parábolas (37-71)
c. Sobre los Astros (72-82)
d. Sobre las visiones (83-90)
e. Sobre las semanas (91-93)
f. Sobre la edificación (94-105).

Los capítulos sobre los ángeles o los vigilantes $(1-36)^{9}$ contienen los viajes realizados por Henoc entre la tierra, el cielo y el infierno. Se habla sobre el juicio final futuro, la caída de los ángeles y el castigo que reciben por Dios por haberse fijado en las hijas de los hombres y haber procreado a los gigantes "héroes» de la antigüedad. ${ }^{10}$

El Henoc fue venerado y utilizado por algunos Padres de la Iglesia, como Clemente de Alejandría, Tertuliano, etc. Probablemente alguno de ellos, o terceros, interpolaron en el libro, específicamente en el capítulo dos, en el tema referente al Mesías, pues se nota un lenguaje cristiano con respeto a la figura del «hijo del hombre».

Con respecto al libro apócrifo de la Ascensión de Moisés, los estudiosos están de acuerdo en confirmar que inicialmente eran dos libros independientes y posteriormente editados juntos. El libro, compuesto solamente de doce capítulos, lleva el nombre de Testamento de Moisés y narra los últimos acontecimientos de la vida del 'Salvado de las aguas' antes de que los hebreos entren a la tierra prometida. En la obra se resaltan las figuras de Josué y de Taxo, este último aun no ubicado en los libros canónicos del Antiguo Testamento. Se caracteriza por su argumento en defensa de la Torà

9 Solamente hago referencia a la primera parte del libro, por estar relacionado directamente con el tema investigado.

10 Una referencia a esta leyenda judía, la encontramos en el capítulo seis del libro del Génesis. 
y las tradiciones religiosas del pueblo, frente a las persecuciones que les toca vivir, especialmente por fuerzas extranjeras.

La obra, originalmente escrita en hebreo y luego traducida al griego, ha llegado en una versión latina. Tanto su autor como el medio de origen, se encuentra en el seno de una secta judía, parcialmente cercana a la ideología de los Esenios. Fue escrita en su totalidad en el siglo I d. C., entre los años 7 y 30 .

Según testimonios patrísticos antiguos, existía una considerable cantidad de escritos atribuidos a Moisés, durante el primer siglo de la era cristiana, entre ellos, sobresalía el Testamento y la Ascensión de Moisés. A partir de lo mencionado, se puede afirmar la importancia de la imagen de Moisés en la promoción de la práctica de la denominada ley mosaica en tiempos de imposición extranjera en Palestina. También, para defender la existencia del libro de la Ascensión de Moisés se debe tener presente la tradición enseñada por Flavio Josefo, que refiere a la «desaparición» y no a la muerte de Moisés. Esta aseveración la vemos reflejada en la transfiguración de Jesús en el monte Tabor (Mt. 17,1-9). ${ }^{11}$

\section{EL CANON JUDÍO}

\section{I. El téRMINO «CANON»}

El reconocimiento de los libros que formarían parte de las Sagradas Escrituras fue una tarea primordial que no abarcó un momento específico de la historia

11 Cabe señalar que en las tradiciones rabínicas se considera que tanto Henoc como Elías no han muerto. Para el lector interesado en ampliar los datos científicos se sugiere consultar la obra de Alejandro Diez Macho: Apócrifos del Antiguo Testamento, que por motivos de extensión, no podemos abarcar por completo en el presente trabajo. 
de la Iglesia católica ${ }^{12}$ o de la Qahal judía, sino diversas épocas. Este se

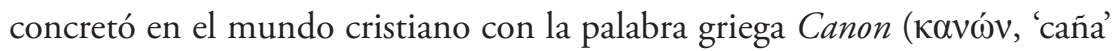
o 'vara'), que se utilizará también para el mundo judío para hacer referencia a la lista oficial y universal de un cuerpo o conjunto de libros, reconocidos como inspirados por Dios. Por lo tanto, son considerados sagrados dentro de un sistema religioso, pues constituyen la regla o norma, para la fe y la vida del creyente.

En el judaísmo la preocupación se generaliza a partir del siglo II a. C., cuando prolifera una gran cantidad de libros religiosos y se siente la necesidad de reconocerlos como inspirados o no. Para que esto suceda los escritos debía cumplir ciertos requisitos: escritos en hebreo, antigüedad, similitud teológica con la Torà de Esdras, reconocimiento y uso por parte de la comunidad, entre otros.

Para mediados del siglo II a. C., se puede observar que el judaísmo hace uso de tres «bloques» de libros ${ }^{13}$ considerados como inspirados, pero aún no reconocidos oficialmente en su totalidad. Se va formando, entonces, las Escrituras, la futura TaNaKo Biblia hebrea. Estos tres bloques de libros serían denominados Torà (Ley), Nebiim (Profetas) y Ketubiim Ketubim (Escritos).

$\mathrm{Al}$ respecto, el evangelista Lucas presenta un claro ejemplo de dicha clasificación: las palabras que Cristo resucitado dirige a sus discípulos.

12 Por ejemplo, el proceso de canonización de los libros inspirados dentro de la Iglesia católica, abarcó desde el siglo II hasta el siglo xvi d. C., específicamente, el canon católico se cierra mediante promulgación oficial dogmática (Concilio de Trento, sesión del 08 de abril de 1546).

13 El prólogo del traductor griego del Eclesiástico (c. 130 a. C.) habla de la Ley, los Profetas y los otros libros que les sucedieron, lo que atestigua la división tripartita que se hizo después clásica (Ramos 1966:166). 
Después les dijo: «Estas son aquellas palabras mías que os hablé cuando todavía estaba con vosotros: "Es necesario que se cumpla todo lo que está escrito en la Ley de Moisés, en los Profetas y en los Salmos acerca de mí.” $Y$, entonces, abrió sus inteligencias para que comprendieran las Escrituras. $(24,44-45)$

Por otra parte, dentro de la TaNaK, ocupa un lugar privilegiado la Torà, pues contiene la revelación directa que hizo Dios a Moisés; mientras que los libros que comprenden Nebiim (Profetas) y Ketubiim (Escritos), orientan sus enseñanzas y mensajes a partir de la Torá. «A pesar de todo y hablando en general, los profetas y los escritos comparten las cualidades de la Torà. Todos ellos son considerados Sagradas Escrituras. Todos ellos manchan las manos» ${ }^{14}$ (Schurer 1985: 422).

Finalmente, se tiene conocimiento sobre la cantidad de libros que fueron inicialmente reconocidos como sagrados. El dato proviene del principal historiador judío del siglo I d. C., Flavio Josefo. Él afirma explícitamente que «entre los judíos solamente veintidós libros eran fidedignos [...] cierto que no los enumera uno por uno» (Schurer 1985: 419).

${ }^{14}$ La expresión: «mancha las manos» fue acuñada por el judaísmo rabínico para hacer referencia a los libros considerados como santos. 


\begin{tabular}{|c|c|c|c|}
\hline \multirow{5}{*}{ TaNaK } & $\begin{array}{l}\text { LEY } \\
(\text { Torà) }\end{array}$ & $\begin{array}{l}\text { Génesis } \\
\text { Éxodo } \\
\text { Levítico } \\
\text { Números } \\
\text { Deuteronon }\end{array}$ & \\
\hline & \multirow{3}{*}{$\begin{array}{c}\text { PROFETAS } \\
\text { (Nebiim) }\end{array}$} & Anteriores & $\begin{array}{l}\text { Josué } \\
\text { Jueces } \\
\text { Samuel (2) } \\
\text { Reyes (2) }\end{array}$ \\
\hline & & Posteriores & $\begin{array}{l}\text { Isaías } \\
\text { Jeremías } \\
\text { Ezequiel }\end{array}$ \\
\hline & & 12 profetas & $\begin{array}{l}\text { Oseas, Joel } \\
\text { Amós, Abdías } \\
\text { Nahúm, Miqueas } \\
\text { Jonás, Habacuc } \\
\text { Sofonías, Ageo } \\
\text { Zacarías, Malaquías }\end{array}$ \\
\hline & $\begin{array}{c}\text { ESCRITOS } \\
\text { (Ketubiim) }\end{array}$ & \multicolumn{2}{|c|}{$\begin{array}{l}\text { Salmos } \\
\text { Job } \\
\text { Proverbios } \\
\text { Rut } \\
\text { Cantar de los cantares } \\
\text { Qohelet } \\
\text { Lamentaciones } \\
\text { Ester } \\
\text { Daniel } \\
\text { Esdras-Nehemías } \\
\text { Crónicas (2) }\end{array}$} \\
\hline
\end{tabular}

Cuadro 1: La Biblia hebrea (Fuente: Paul 1985:62) 


\subsection{El Reconocimiento de los Escritos en el JUdaÍsmo}

Como lo afirma Dan Jaffè, «el proceso de canonización de la Biblia hebrea fue largo y duró varios siglos» (2009:26). Por ello, se considera necesario ubicar los momentos claves de dicho proceso en la historia de Israel.

Los primeros libros en ser reconocidos oficialmente como inspirados -y, por lo tanto, aceptados por la comunidad judía- fueron los que conformarían la Torà (Ley). Las referencias más antiguas que se conservan sobre la aceptación de una parte de la Torà, se remonta al año 622 a. C. (s. VII), y han quedado registrado en los capítulos veintidós y veintitrés del segundo libro de los Reyes.

En el capítulo veintidós se describe cómo, durante unas reparaciones en el Templo por mandato del rey Josías, el sumo sacerdote Helequías, descubre casualmente «el libro de la ley en la casa de Yavè» (v.8). En el siguiente se detalla la gran reforma que realiza Josías a partir del reconocimiento oficial de dicho libro:

El rey ordenó que todos los ancianos de Judá y de Jerusalén se reunieran en asamblea ante él. Josías subió al templo de Yahvè con todos los hombres de Judá y todos los habitantes de Jerusalén, los sacerdotes, los profetas y todo el pueblo, desde los más jóvenes a los más ancianos y leyó ante ellos el texto completo del rollo de la alianza hallado en el templo de Yahvè. El rey se situó en pie junto a la columna y celebró el rito de la alianza ante Yahvè: que ellos deberían seguir a Yahvè y guardar sus mandamientos, sus testimonios y sus preceptos con todo el corazón y toda el alma, y cumplir los términos de esta alianza tal como estaba en el rollo. Todo el pueblo se comprometió a la alianza. (2 Re. 23, 1-3) 
Como se mencionó, el hallazgo de Helequìas era una parte de la Torà, comprendía ciertos relatos del Génesis y el Éxodo; pero la importancia del mismo radica en el descubrimiento de «lo que ahora es el Deuteronomio ${ }^{15}$ 12 a 26» (Arens 1990: 105), que hasta ese momento había sido desconocido.

No obstante, la tradición judía considera la canonización de la Torà como obra realizada por Esdras (s. v a.C.) durante el retorno del exilio babilónico. Este sacerdote y escriba la había redactado y conservado, y al retornar a Jerusalén la hizo conocida por el pueblo. Según el libro de Nehemías este momento histórico ${ }^{16}$ se desarrolla de la siguiente manera:

Llegado el mes séptimo, todo el pueblo se congregó como un solo hombre en la plaza que está delante de la puerta del agua. Dijeron al escriba Esdras que trajera el libro de la Ley de Moisés que Yahvè había prescrito a Israel. Trajo el escriba Esdras la Ley ante la asamblea integrada por hombres, mujeres y todos los que tenían uso de razón. Era el día uno del mes séptimo. Leyó una parte en la plaza que estaba delante de la puerta del agua, desde el alba hasta el mediodía [...], Esdras abrió el libro a la vista de todo el pueblo - pues estaba más alto que el resto de la gente- y al abrirlo el pueblo entero, se puso de pie. Esdras bendijo a Yahvè, el Dios grande; y todo el pueblo alzando las manos respondió: “Amén, Amén!» e inclinándose se postraron ante Yahvè, rostro en tierra. [...] Y Esdras leyó en el libro de la Ley de Dios, aclarando e interpretando el sentido, para que comprendieran la lectura. (Neh. 8,1-8)

15 «[...] significa segunda ley, y fue llamado así por estar ubicado [...] después del conjunto de leyes que ocupan los libros de Levítico y Números (Biblia latinoamericana. 2005: 164)».

16444 o 435 a.C. (Cf. Senderey 1959:132). 
A diferencia de la reforma de Josías, que se basaba en el conocimiento básico y aplicativo de la Torà por parte del pueblo, «el significado de la figura de Esdras reside en los desvelos del personaje por la difusión de la Torà. Una de sus mayores preocupaciones fue la lectura pública de la Torà los lunes y jueves; fundó numerosas escuelas para el estudio de la Torà» (Maier 1996:145), por parte del hombre común y no solamente de la clase sacerdotal.

Nuevamente se debe señalar que la Torà de Esdras no era en su totalidad los cinco libros que ahora conocemos. ${ }^{17}$ Con el tiempo se fueron uniendo partes adicionales que se encontraban dispersas. Es así como «no recibió reconocimiento canónico hasta que empezó a leerse junto con los escritos de los profetas en las sinagogas hacia el siglo tercero» (Arens 1990: 106).

Con respecto al segundo momento, el correspondiente al reconocimiento de los Nebiim (Profetas) es amplio. La redacción de los libros proféticos - entre los cuales los judíos incluyen algunos libros que para el mundo católico corresponden al género histórico ${ }^{18}$ - abarcó varios siglos. Los libros proféticos fueron leídos junto a los libros de la Torà, sin embargo, para inicios del siglo ir a.C., en tiempos de Jesús ben Sira, constituían un bloque venerable como la Ley (Cf. Arens 1990:106). Así también lo reafirma F. F. Ramos: «Eclo. 46-49 (hacia el 180 a.C.): Después del elogio de los Patriarcas se hace igualmente, y siguiendo el orden de los libros del Canon, el de los otros personajes que figuran en los libros de los profetas anteriores y posteriores [...]. Lo cual corrobora la existencia de la colección ya completa y con valor normativo» (1966:166).

17 El cristianismo utiliza la palabra Pentateuco ('cinco rollos') para referirse a la Ley o Torà. 18 Los libros proféticos en el judaísmo se dividen en Nebiim Risonim (profetas anteriores), en ellos se incluye los libros Josué, Jueces, 1-2 Samuel, 1-2 Reyes, y Nebiim Aharonim (profetas posteriores), Isaías, Jeremías, Ezequiel, etc. 
Para analizar el último momento en que se norma y/o se reconoce oficialmente el grupo de libros de la TaNaK, correspondientes a Ketubiim (Escritos), es necesario explicar algunos aspectos del primer siglo de la era cristiana. Específicamente, interesa para este fin lo ocurrido antes y después de la destrucción del Templo en el año 70 d. C.

Desde el siglo II a. C., la sociedad judía de Palestina experimentó la aparición de varias comunidades religiosas (Esenios, Saduceos, Fariseos, etc.), las cuales se fortalecieron en el seno del judaísmo en el siglo i. Cada una tenía sus propias características que las diferencian unas de otras y también con la casta sacerdotal oficial. Si se las estudia detenidamente es posible percibir que son "pequeños universos», es decir, tenían su propia organización, su propio estilo de vida, su propia literatura interna y hasta su propia forma de interpretar la Torà.

Existen dos ejemplos que pueden ilustrar lo anteriormente mencionado. El primero es la comunidad de los Esenios, una comunidad judía de la cual se tenía referencia solamente por autores antiguos. Gracias a la gran cantidad de rollos descubierto en el siglo xx se puedo entender su teología, su organización, su forma de vivir, etc. El segundo, que ayudará a respaldar la tesis del presente trabajo, es la variedad de interpretaciones que se daba a la Torà dentro de las escuelas farisaicas, las cuales giraban alrededor de un emblemático maestro. A mediados del siglo I de la era cristiana sobresalieron dos maestros fariseos: Hillel ${ }^{19}$ y Shammai. Ambos rivalizaban entre sí, sobre todo, por la forma de interpretar la Torà. El primero era de la escuela liberal de interpretación, mientras que el segundo pertenecía a la más estricta.

19 Según el Talmud, fue abuelo de Gamaliel I. Considero necesario señalar que este Gamaliel es el mismo a quien se hace referencia en el proceso de Pedro y Juan (Hechos 5 , 33-42) y fue maestro de Saulo, como él mismo lo sustenta (Hechos 22, 3). 
En este año 70 d. C., la destrucción del segundo Templo provocó importantes cambios en el seno de la sociedad judía» (Jaffè 2009:19). Entre las principales consecuencias de la destrucción ocasionada por los romanos tenemos la desaparición total del Templo y de la casta sacerdotal. Asimismo, se inicia la diáspora del pueblo judío. ${ }^{20}$

Este año pudo haber marcado el final del judaísmo, si no fuera por la comunidad farisea. ${ }^{21}$ Fue la única que pudo sobrevivir a la destrucción y supuso la unificación de todo lo que quedaba de las otras comunidades en torno a "Los sabios de Yabne»"22 (Jaffè 2009:19). Los maestros de Yabne, bajo la tutela de Yohanàn ben Zakai (70-90? d. C.), tuvieron la tarea de reorganizar el judaísmo ${ }^{23}$ basándose, sobre todo, en:

- La figura del rabino, quien educa en la fe a la comunidad (ya no existe la casta sacerdotal, ni grupos religiosos).

- La Sinagoga toma importancia como centro de culto, en ausencia del Templo.

- La reorganización del calendario religioso judío (fiestas).

Según la tradición, su principal obra se realizará bajo la dirección de Gamaliel II ${ }^{24}$ (96-115 d. C.): el reconocimiento del último bloque de libros como inspirados, que comprende la TaNaK, es decir, Ketubiim. Aunque

20 La diáspora duró hasta mediados del siglo xx. En 1948, se crea el moderno Estado de Israel.

21 Específicamente «la rama farisaica de obediencia hillelita» (Diez 1984: 55).

22 Ciudad puerto en la parte sur de Palestina, después de la destrucción de Jerusalén (70 d. C.) pasó a ser el centro de estudios religiosos.

23 En Yabne nace el «judaísmo rabínico», que es el que perdura hasta nuestros días en sus diversas ramas y/o corrientes.

24 Nieto de Gamaliel I. 
eran ya considerados como tales desde inicios del siglo I, «el estatuto de estos libros fue discutido durante el patriarcado de R. Gamaliel II, y tras numerosos debates ${ }^{25}$ fue admitida su canonicidad» (Jaffè 2009:26).

También se emprendió la enorme tarea de definir el canon de la Biblia hebrea. Esta labor significó fijar cuáles libros deben incluirse en Escrituras Sagradas (Cf. Senderey 1959).

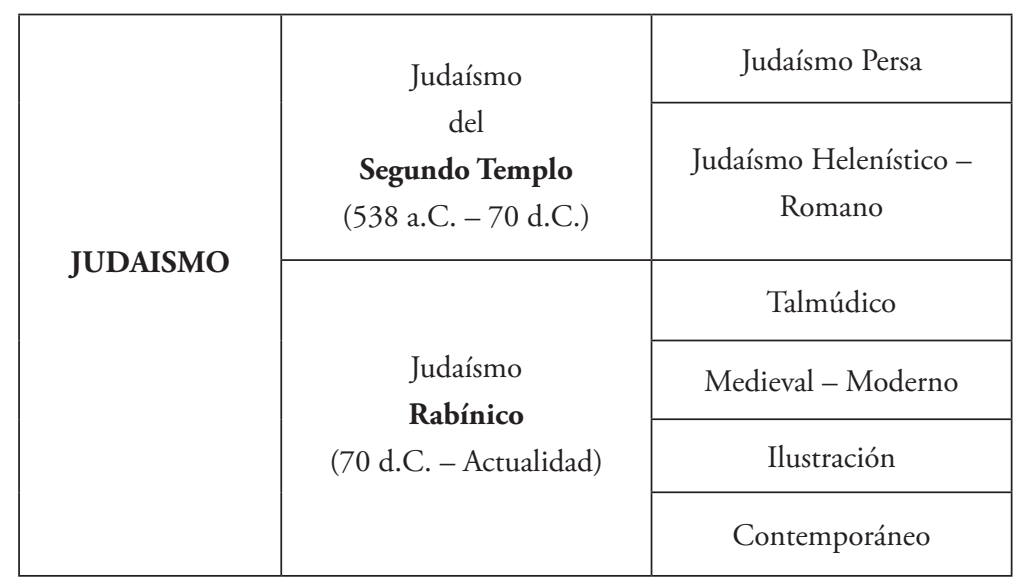

Cuadro 2: División Histórica del Judaísmo (Fuente: Soto 2009:91)

Aunque muchos estudiosos consideran que el canon judío se cerró definitivamente en Yabne (Cf. Diez Macho 1984; Jaffè 2009; Senderey 1959; Schurer 1985), es acertado el comentario que hace Gunter Stemberger al sostener que «el empeño de Yabne en aclarar el status de algunos libros bíblicos toca solo de pasada la cuestión del canon y de ninguna manera significó su fijación definitiva» (2011:21). En otras palabras, en Yabne se inició el interés

25 Algunos libros como Eclesiastés y Cantar de los cantares fueron difíciles de ser reconocidos. 
de reconocer cuáles eran los libros inspirados y que formarían, a futuro, la Biblia hebrea o TaNaK. Este proceso no finalizó durante el gobierno de Gamaliel II, sino hasta ya avanzado el siglo segundo de nuestra era, con la promulgación, en su forma definitiva, del "canon palestinense» ${ }^{26}$ durante «el período Talmúdico» (Maier 1996: 87).

\section{LA CARTA DE JUDAS Y SUS FUENTES APÓCRIFAS}

\section{I. Datos generales de la CARTA}

Para la década del 60 del siglo pasado, llamaba la atención la forma como el alemán K.H. Schelkle calificaba a la carta de Judas: una «hoja volante antiherética» ${ }^{27}$ (Tuñi 2003:406). Dicho calificativo resume en sí la naturaleza de este breve escrito.

Actualmente son más los especialistas que aceptan que no fue Judas, hermano de Santiago, quien escribió la carta. Señalan que el autor quiso llamarla así, pues la referencia a Santiago hace considerar que estaba dirigida a unas comunidades en donde la figura del apóstol era relevante.

No se tiene datos precisos con respecto al autor, pero sí podemos reconocer ciertas características del mismo a partir de la propia carta. El

26 La Septuaginta constituye el llamado «canon alejandrino» por haber sido tradicionalmente asociado con Alejandría (Egipto), donde se habría hecho la traducción al griego de los escritos en hebreo. Era leída y venerada por los judíos de lengua griega, especialmente lejos de Palestina (diáspora). A pesar de haber sido empleada y venerada por tantos judíos (más numerosos que en Palestina) de lengua griega. La Septuaginta nunca fue reconocida como canónica por el judaísmo oficial (rabínico), y eventualmente cayó en desuso. Fue más bien entre los cristianos que se popularizó, pues se leía en las reuniones litúrgicas y se citaba en la predicación y la catequesis (Arens 1990:108).

27 Este y la dirigida a Filemón son las dos cartas más breves (veinticinco versículos) del Nuevo Testamento. 
autor es un hombre que se mueve en dos culturas, la helenista y judía; además, conoce el griego, pues lo redacta con facilidad, y la retórica. En donde sobresale es en el dominio de las ilustraciones y contenidos del Antiguo Testamento y de la existente literatura apócrifa judía. Finalmente, su formación cristiana se ve reflejada en la presentación resumida y breve de la enseñanza transmitida desde los apóstoles.

Considerando que no fue Judas quien escribió la carta, sino un cristiano de la segunda generación, la redacción de la misma debe situarse entre los años 80 y 100 (fines del siglo I d. C.). Aunque Josep-Oriol Tuñi (2003) considera que no son claros los datos en relación al lugar de composición y a los destinatarios, existen indicios que permiten un acercamiento discreto a un conocimiento básico de los mismos. Por ejemplo, a partir del versículo cinco de la carta, Otto Kuss demuestra que los destinatarios de la misma tenían conocimiento sobre las tradiciones del Antiguo Testamento y del folclore judío antiguo, por lo que sugiere «que la carta se dirige a judíos convertidos» (1977:406). Era una o varias comunidades ubicadas fuera de la Palestina, pero cercana a ella, en donde el elemento judío sobresale (judeocristianos), pero vive el peligro del desorden moral provocado por miembros de origen pagano (helenista) que se han integrado a la Iglesia, como lo demuestra el versículo cuarto de la carta. En conclusión, tanto el autor como sus destinatarios son «judeocristianos helenistas» (Mertens 1989:486).

El tema central de la carta se puede resumir de la siguiente manera: «Estar atentos, frente a los infiltrados». Todo el escrito detalla las dificultades que tuvieron que afrontar los miembros de las comunidades ante la 
presencia de un reducido grupo de personas que buscan la división. ${ }^{28}$ Ante esta situación, el autor responde basándose en «los aspectos fundamentales de la fe tradicional» (Tuñi 2003:375), aunque para ello tenga que citar libros apócrifos judíos

- Encabezamiento de tipo epistolar

- Ocasión y finalidad del escrito

- Argumentos e incentivas contra los intrusos

- Exhortaciones a la comunidad

- Doxología final.

Cuadro 3: Estructura de la carta de Judas (Fuente: Tuñi 2003:373)

La referencia a ciertos libros apócrifos trajo como consecuencia que, desde el segundo siglo de nuestra era, la carta de Judas haya sido utilizada con reserva:

Las iglesias de Roma, Cartago y Alejandría acogieron ya hacia el 200 la carta de Judas en el Canon. Antioquia la reconoció como canónica solo hacia el 400. (Mertens 1989:486)

[...]No hay constancia de su utilización o de su valoración como escrito inspirado hasta el llamado Canon de Muratori (hacia el 200). Resulta sorprendente que este documento, probablemente romano, mencione a Judas entre los escritos que se tiene como inspirado [...] hay que esperar a Clemente de Alejandría para encontrar citas de Judas. Orígenes lo usa pero no deja de notar

28 La palabra libertinaje en el versículo cuarto de la carta, hace pensar a los estudiosos que se refiere a grupos o corrientes llamadas «libertinistas» o «antinómicas» que existían en ciertas zonas helenistas. 
reservas, a causa de su utilización de los apócrifos, Jerónimo deja constancia de que todavía existen dudas acerca de su canonicidad. Las Iglesias de Siria (Antioquia y Siria oriental) no la mencionan para nada hasta fines del siglo v. (Tuñi 2003:378)

\subsection{LA PRESENCIA APÓCRIFA EN LA CARTA}

La variedad de referencias que utiliza del mismo lo hace un escrito único dentro del Nuevo Testamento. Se citará el uso oriental de la numerología para resaltar una idea o argumento de la carta. Por ejemplo, el número tres ${ }^{29}$ aparece en el versículo dos (misericordia, paz y amor) y en el versículo once (Caín, Balaán y Corè). El énfasis que pone el autor en el versículo catorce para identificar a Henoc como el séptimo ${ }^{30}$ patriarca. Finalmente, el uso del libro de Zacarías $(3,2)$ - sin citarlo- mencionando en el versículo nueve.

Mas lo que llama más la atención es la referencia a cinco leyendas tradicionales que se encuentran registradas en apócrifos judíos (Kuss 1977:427). Estas son el pecado y castigo de los ángeles (v.6), las ciudades deshonestas de Sodoma y Gomorra (v.7), la disputa entre Miguel y el demonio por el cadáver de Moisés (v.9), la profecía de Balaán (v.11) y la profecía de Henoc (v.14ss).

Es evidente la familiaridad del autor de la carta con dos géneros literarios. Estos son el apocalíptico y, al parecer, el testamento (Cf. Diez 1984). Por lo tanto, en la carta se «presenta todas las huellas de la manera de pensar y de expresarse del judaísmo inmediatamente anterior al cristianismo» (Kuss 1977:427).

29 Significa: 'permanente', 'grandioso'.

30 El número siete significa 'justo, perfecto, predilecto de Dios'. 
Al menos, el autor de la carta de Judas conocía el Henoc etiópico (Cf. Diez 1984) y las comunidades cristianas lo utilizaban «en ocasiones quizá tanto como un libro de la Sagrada Escritura» (Kuss 1977:426).

\begin{tabular}{|c|c|}
\hline 1 Henoc 1,9 & Judas 14-15 \\
\hline $\begin{array}{l}\text { He aquí que llegará con miríadas de } \\
\text { santos para hacer justicia, destruir } \\
\text { a los impíos y contender con todos } \\
\text { los mortales por cuanto hicieron y } \\
\text { cometieron contra él los pecadores } \\
\text { e impíos. }\end{array}$ & $\begin{array}{l}\text { Henoc, el séptimo después de Adán, } \\
\text { profetizó ya sobre ellos: «Mirad, } \\
\text { el Señor ha venido con sus santas } \\
\text { miríadas para realizar el juicio contra } \\
\text { todos y dejar convictos a todos los } \\
\text { impíos de todas las obras de impiedad } \\
\text { que realizaron y de todas las palabras } \\
\text { duras que hablaron contra él los } \\
\text { pecadores impíos.» }\end{array}$ \\
\hline
\end{tabular}
«La profecía de Henoc»

\begin{tabular}{|l|l|}
\hline \multicolumn{1}{|c|}{$\mathbf{1}$ Henoc 6,1-12 } & \multicolumn{1}{|c|}{ Judas 6 } \\
\hline $\begin{array}{l}\text { En aquellos días, cuando se } \\
\text { multiplicaron los hijos de los } \\
\text { hombres, sucedió que les nacieron }\end{array}$ & $\begin{array}{l}\text { [..] y además que a los ángeles, que } \\
\text { no mantuvieron su dignidad, sino } \\
\text { que abandonaron su propia morada, }\end{array}$ \\
hijas bellas y hermosas. Las vieron & $\begin{array}{l}\text { los tiene guardados con ligaduras } \\
\text { eternas bajo tinieblas para el juicio }\end{array}$ \\
los ángeles, los hijos de los cielos, \\
las desearon y se dijeron: Ea, \\
escojámonos de entre los humanos \\
y engendremos hijos. Semyaza, su \\
jefe, les dijo: Temo que no queráis \\
que tal acción llegue a ejecutarse y \\
sea yo sólo quien pague por tamaño \\
pecado. $[\ldots]$
\end{tabular}

«El pecado y castigo de los ángeles»

31 Especialmente, escritores griegos. 
Con respecto al uso de la Ascensión de Moisés como fuente para la carta de Judas, se debe tener en cuenta que no se encuentra la cita en las actuales reproducciones de dicho libro. Coincidiendo con la afirmación de Alejandro Diez Macho: «El libro conservado [...] es en realidad un “Testamento" y no una "Asunción” de Moisés» (1984: 219). Esto significa que debemos confiar en las referencias que hacen los escritores cristianos antiguos —entre ellos la carta de Judas - de la existencia una leyenda sobre la disputa del cadáver de Moisés, por parte del arcángel Miguel y el diablo, leyenda que inicialmente habría contenido la obra.

Por ejemplo, entre los principales escritores cristianos ${ }^{31}$ que hacen referencia a la existencia de dicha leyenda en la Ascensión de Moisés, tenemos a Clemente de Alejandría, Orígenes, Dídimo de Alejandría, Epifanio de Salamina, Evodio de Antioquia, Gelasio, Apolinar, entre otros.

\section{Judas 9}

Sin embargo, el arcángel Miguel, cuando oponiéndose al diablo discutía sobre el cuerpo de Moisés, no se atrevió a lanzarle un juicio injurioso, sino que dijo: Que el Señor te condene.

Finalmente, si se imagina por un momento estar dentro o fuera de la Palestina del primer siglo, se puede percibir cómo la literatura judía (que ya existe) y la cristiana (que va surgiendo) se encuentran libremente en la atmosfera. Solamente así se entiende que obras como el libro de Henoc y la Ascensión de Moisés gozaron de aceptación por parte de algunos grupos o movimientos religiosos judíos, como también por parte de la Iglesia naciente. 


\section{LA LITERATURA APÓCRIFA JUDÍA EN EL CRISTIANISMO ANTIGUO}

Nadie puede dudar que los primeros integrantes de la Iglesia primitiva, aquella que nace en Jerusalén, sean judíos. Lo confirma la declaración conciliar Nostra Aetate, cuando sostiene «que los Apóstoles, fundamentos y columnas de la Iglesia, nacieron del pueblo judío, así como muchísimos de aquellos primeros discípulos que anunciaron al mundo el Evangelio de Cristo» (N. 4).

Cuando el libro de los Hechos de los Apóstoles presenta a los cristianos helenistas, no hace otra cosa que referirse a judíos provenientes de la diáspora y que conviven con otros patrones culturales. Es decir, aquellos «hombres nuevos», «nuevos cristianos», que formaban parte de la naciente Iglesia, venían con todo un rico patrimonio cultural, obtenido mediante la tradición de sus padres y que en ciertos casos lo utilizaron para poder trasmitir una verdad pastoral. Por ello, el uso de leyendas, cuentos, alegorías, etc., por parte de los primeros pastores eclesiales, no deben ser considerados como un impedimento o peligro para la enseñanza del evangelio dentro de las primeras comunidades cristianas. En palabras de Otto Kuss:

[...] todo lector que esté familiarizado con el contenido de aquellas leyendas judías puede darse cuenta en seguida que el autor [...] toma material de estas fuentes, es decir, los cita. Tales

32 Un ejemplo claro de lo anteriormente mencionado es la historia de la evangelización de América. Se debe recordar que los primeros evangelizadores tuvieron que hacer uso de los elementos religiosos nativos para poder hacer llegar la doctrina católica. La catequesis se daba a partir de las analogías que se podían encontrar en el mundo andino y el catolicismo. Este tema fue muy bien trabajado por el ya fallecido sacerdote jesuita Manuel Marzal, quien lo estudió como «sincretismo». 
materiales judíos no son el objeto de su enseñanza, pero se vale de ellos para ilustrar su instrucción. [...] Es preciso distinguir entre las verdades que el autor enseña y la forma en que las presenta. (1977: 429 , las cursivas son nuestras $)^{32}$

Sin embargo, la literatura apócrifa judía fue rechazada por el judaísmo rabínico que iba apareciendo a fines del siglo primero de nuestra era, ya que esta literatura había sido considerada y valorada inicialmente por el cristianismo naciente. La literatura apócrifa reconocida fue especialmente la que estaba compuesta por obras que contenían temas escatológicos, pues se debe recordar que las primeras comunidades cristianas vivían a la expectativa de la Parusía o segunda venida del Señor. «El aprecio cristiano aumentó el desprecio judío» (Diez 1984:97). Asimismo, este respeto a dichas obras se ve reflejado en las diversas copias que nos han llegado, especialmente por medio de las Iglesias orientales, aunque con el transcurrir de los siglos, también fueron las Iglesias las que prohibieron usarlos en la vida cultural de la comunidad.

Finalmente, la literatura apócrifa - judía o cristiana- tiene un gran valor para conocer el contexto situacional que le tocó vivir al judaísmo rabínico y al cristianismo antiguo. Dichos documentos deben ser considerados como fuente para la mejor comprensión de los relatos de los evangelios, la forma de vida de los primeros cristianos, sus preocupaciones, entre otros. 


\section{BIBLIOGRAFÍA}

Arens KuCKelKorn, Eduardo

1990 La Biblia sin mitos. Lima: Paulinas.

Brown, Raymond E.

1972 Comentario biblico San Jerónimo. Tomo IV. Madrid: Cristiandad.

Chico Gonzalez, Pedro

2006 Diccionario de catequesis y pedagogía religiosa. Tomo I. Lima: Bruño.

Diez Macho, Alejandro

1984 Apócrifos del Antiguo Testamento. Tomos I - V. Madrid: Ediciones Cristiandad.

Gonzalo Maeso, David

1960 Manual de historia de la literatura hebrea. Madrid: Editorial Gredos.

JAFFÉ, Dan

2009 El talmudy los orígenes del cristianismo. Bilbao: Desclée De Brouwer.

LEAL, Juan

1967 La Sagrada Escritura: Nuevo Testamento. Tomo III. Madrid: BAC.

Kuss, Otto y Johann, MICHL

1977 Cartas a los hebreos, cartas católicas. Barcelona: Herder. 
Maier, Johann y Peter Schafer

1996 Diccionario del judaísmo. Navarra: Verbo Divino.

Mertens, Heinrich A.

1989 Manual de la Biblia. Barcelona: Herder.

Paul, André

1985 «La inspiración y el canon de las Escrituras». Cuadernos Bíblicos N. 49. Navarra: Verbo Divino.

Ramos, F.F. (Coord.)

1966 Introducción general a la Sagrada Escritura. Alcalá: Casa de la Biblia.

Rodriguez Carmona, Antonio

2002 La religión judia: historia y teología. Madrid: BAC.

Santos Otero, Aurelio de

1999 Los evangelios apócrifos. Madrid: BAC.

SCHURER, Emil

1985 Historia del pueblo judio en tiempos de Jesús (175 a.C. - 135 d.C.). Tomo II. Madrid: Ediciones Cristiandad.

Senderey, M

1959 Breve historia del pueblo de Israel. Tomo I. Buenos Aires: Editorial Yehuda. 


\section{PEDRO SOTO CANALES}

Soto Canales, Pedro P.

2009 «La enseñanza rabínica en el primer siglo de la era cristiana». STUDIUM VERITATIS, N.12-13, año 7, pp.89-122. Lima.

Stemberger, Gunter

2011 El judaísmo clásico: cultura e historia del periodo rabinico. Madrid: Editorial Trotta.

TuñI, Josep-Oriol y Xavier Alegre

2003 Escritos joánicos y cartas católicas. Navarra: Verbo Divino. 